\title{
A escolha do cônjuge
}

\author{
Maria Stella Ferreira Levy*
}

\begin{abstract}
Enfocando os tópicos namoro e noivado, idade ao casar e diferenças de idade entre os cônjuges, este artigo caminha por três grandes períodos históricos: o período colonial; o século XIX até finais do XX; e o início do século XXI. Trata-se de uma análise transdisciplinar dos pontos de vista histórico, social, demográfico, legal e jurídico, focalizando o desenrolar dessas situações seja por persistências e/ou mudanças; quem e quais são os atores envolvidos e sua importância nas escolhas dos futuros nubentes. No início, a seleção era fundada no parentesco e no território, privilegiando a grande rede familiar solidária no enfrentamento das dificuldades de sobrevivência. Com os avanços da industrialização, da urbanização, da tecnologia e de comunicação, além do crescimento da importância das pessoas, as escolhas foram se transformando, diminuindo a dependência da estrutura familiar e aumentando a escolha pessoal e afetiva, influenciadas pelas variadas formas de mudança social, demográfica, jurídica.
\end{abstract}

Palavras-chave: Escolha do cônjuge. Namoro. Noivado. Idade dos cônjuges.

\section{Introdução}

Para Lévi-Strauss, o sistema de parentesco, as regras de casamento e os grupos de descendência constituem um conjunto coordenado, cuja função é assegurar, pela costura dos laços consanguíneos e afins, a permanência do grupo social. Podem ser considerados como a fábrica (blueprint), cujo mecanismo retira (pumps) as mulheres de suas famílias consanguíneas para redistribuí-las nos grupos de afinidade, resultando desse processo a criação de novos grupos consanguíneos e dando, assim, continuidade à vida em sociedade (LÉVI-STRAUSS, 1954, p. 546).

A escolha do cônjuge em todas as sociedades humanas, sejam tribais, civilizadas, rurais, urbanas, tradicionais ou modernas, tem suas regras. Cientistas sociais veem esse processo de escolha funcionando na sociedade como um sistema de mercado, em que a beleza da mulher pode ser tão valiosa quanto a riqueza, o futuro e tantos outros atributos do homem. Aliás, obras de moralistas portugueses dos séculos XVI e XVII, escritas por homens para homens, cuja ética e moral provinham do cristianismo medieval, em seguida engessadas pelo Concílio de Trento, os estimulam a casarem, ditando regras sobre como deveriam escoIher suas futuras esposas, considerando as diferenças de idade entre eles, categorias do tipo nobres e plebeus, ricos e pobres, formosura e feiúra, aconselhando o meio termo (ALMEIDA, 1988/1989; AZEVEDO, 1986, p. 67).

Essa escolha dos cônjuges não era apenas assunto da ordem familiar entre os povos primitivos: entre nós, além de

\footnotetext{
* Professora associada do Departamento de Epidemiologia, Faculdade de Saúde Pública da USP. Bacharel em Ciência Sociais e Direito, MA em Antropologia pela Universidade de Wisconsin, Madison, doutora em Saúde Pública pela FSP/ USP e em Direito Civil pela UFMG.
} 
ser regida pelo costume, era também regulada pelas leis do Reino e da Igreja, como os esponsais. Entretanto, os arranjos de casamento não deixavam de ser uma questão de âmbito familiar, especialmente entre as classes abastadas, e no geral independiam da vontade dos nubentes, que sequer eram consultados. Nos vários grupos sociais, no tempo da Colônia, ainda eram as moças controladas pelos pais e mães, devido ao valor imputado à virgindade e à economia da família. Esses arranjos eram tão fortemente controlados que, caso os interessados se casassem sem autorização paterna ou materna, segundo as Ordenações Filipinas, podiam ser deserdados, só não sofrendo penalidade se o pretendente fosse de melhor condição do que o escolhido pelos pais (ALMEIDA, 1870, livro V, título XXII). Também eram execrados com penas duríssimas, como a nulidade do casamento, os inter-religião, ou uniões com estrangeiros, infiéis, etc.

Os manuais de casamento dos séculos XVI e XVII mencionados (ALMEIDA, 1988/89) recomendavam várias atitudes e comportamentos em relação a essa escoIha, para que os casamentos dessem certo e fossem "bons", estimulando preferencialmente os casamentos intraclasses e afastando os interclasses com penalidades.

A forma de escolher os cônjuges por quem de interesse ou de direito variou com o tempo e o lugar, e inclui duas etapas: o namoro e depois o noivado, esta última conhecida entre nós como noivado oficial:

Denominam-se regras do casamento os critérios e as normas, derivados da organização social, dos sistemas de parentesco e dos tabus de incesto, que determinam a escolha dos cônjuges e a ratificação das uniões conjugais (...) a constituição da família é mediada por certas regras ritualizadas segundo determinados padrões válidos em cada cultura (...). Todo casamento é, assim, precedido necessariamente de ajustes e entendimentos entre os futuros cônjuges ou entre suas famílias, e ainda entre intermediários socialmente definidos. (AZEVEDO, 1986, p.4)

No Japão, por exemplo, o casamento como questão de família, pelo menos até meados do século $X X$, fazia-se pela intermediação da figura do na kao dô, uma espécie de padrinho que, conhecendo as famílias, seus integrantes e tendo a sua consideração, vai em busca do par que pensa adequado para se casar. Ele também pode preencher o papel de $m i$ iay, apresentando os noivos entre si, que provavelmente até esse momento não se conheciam.

Sob o regime patriarcal e familista do Brasil colonial, a escolha de cônjuges nas classes abastadas, tanto para as filhas como para os filhos, era um privilégio quase exclusivo do pater familias, pois

o casamento interessava à solidariedade e à integridade dos grandes grupos de parentesco nos quais se apoiavam a ordem social, a economia, a política, e a própria realização pessoal dos indivíduos. As crônicas históricas, o folclore, a literatura de ficção, a documentação judiciária não deixam dúvidas a respeito, muito embora também registrem as resistências e as insubmissões que o amor romântico sempre ofereceu ao casamento arranjado pelos pais sem a anuência prévia dos futuros cônjuges. (AZEVEDO, 1986, p. 7)

\section{O período colonial}

\section{Namoro, noivado}

Nas classes socialmente privilegiadas do período colonial no Nordeste, raramente a escolha do pretendente quanto ao casamento era prerrogativa da moça de pouco mais de 13 anos. Gilberto Freyre conta como um viajante estrangeiro relata o pedido de casamento: "certo dia o pai entra na sala de visitas, acompanhado por um cavalheiro desconhecido, às vezes já quase velho ou já maduro. - Minha filha, adverte ele, este é seu futuro esposo". Às vezes o "futuro esposo" era uma surpresa agradável para uma menina de 14 ou 15 anos por se tratar de um jovem pálido de 23 a 25 anos, e o amor romântico se desenvolvia entre os noivos; mas, outras vezes, o "futuro esposo" era "um nouveau riche português, gordo, nédio, lá de meia idade - para uma menina igualmente de quatorze ou quinze anos - pescoço curto 
e mãos grosseiras" (apud AZEVEDO, 1986, p.6-7). ${ }^{1}$

$\mathrm{Na}$ capitania de São Paulo do século XVII, e em parte do XVIII, isolada do governo central do Brasil, não havia sociedades comerciais formais, e a atividade econômica se realizava através da família proprietária, daí a importância das alianças familiares visando o casamento dos filhos, o que ampliava e fortalecia o poder social e econômico do clã. Por conta da mobilidade dos homens para o sertão com as bandeiras, eram alianças de negócios e constituíam a base da prosperidade no Estado. ${ }^{2}$

Segundo Nazzari (2001), o casamento era a forma pela qual se estabelecia nova empresa produtiva, cuja premissa relevante era a escolha do cônjuge, para o qual o dote era parte crucial nesse arranjo, proporcionando ao futuro marido a aquisição de recursos independentes.

A escolha do cônjuge no período coIonial nessas classes abastadas excluía a paixão, a atração física ou o amor, e dependia das razões pessoais do pater familias, evidenciando, assim, a assimetria nas relações, uma vez que a escolha era feita pelos homens, sendo o papel da mulher passivo: ela era ou não escolhida. De acordo com os autores que escreveram sobre esse período, dentro da família, nada era dito ou conversado sobre namoro ou sexo, especialmente diante da presença feminina. A moça tinha de ser virtuosa, honesta, honrada, qualidades não exigidas do marido. Essa noção de honra, para a mulher solteira, significava ser virgem, e a perda da virgindade diminuía, e muito, as chances de casamento.

Quando os próprios interessados resolviam fugir, estavam sujeitos a castigos. Eram previstas penas e indenizações aos sedutores ou raptores nas Ordenações, livro $\mathrm{V}$, título XXIII, quando trata "do que dorme com mulher virgem", estabelecendo uma diferença se essa perda foi por sedução ou pela força. Esse duplo padrão de moralidade que governa as relações entre os sexos em várias partes do mundo, no Brasil, segundo Thales de Azevedo (1986, p.215-216), foi costume derivado das influências em Portugal de vários povos e da larga difusão, entre as classes mais pobres, das uniões sem quaisquer formalidades, bem como dos tipos similares de casamentos surgidos nas classes superiores no século XX, que buscavam casar-se em outros países. Formas de casamento que, mesmo sem validade legal no Brasil, conseguiam alguma validade social.

Sedução era um artifício enganoso empregado para seduzir mulher virgem, agravado se for menor de 17 anos, quando o sedutor consegue um ajuntamento carnal ilícito, do qual resultam a gravidez e o parto; para o rapto é necessário que a mulher seja levada para outro local que não a própria casa. Ambas as situações eram crimes, embora mais grave quando acumulava estupro e rapto, sendo os infratores punidos, senão com o casamento, pelo menos por uma indenização arbitrada pelo julgador e paga pelo sedutor, que, caso ele ou seu pai não tivessem bens, seria degredado para a África e também açoitado se fosse peão. O Concílio de Trento determina que "o que rouba a mulher, ou a receba ou não por esposa, seja obrigado a dotá-la decentemente, a arbítrio do juíz" (SILVA, 1984, p. 74-75). ${ }^{3}$

D. José, rei de Portugal, conjugando suas Leis de 19 de junho de $1775 \mathrm{com}$ a de 29 de novembro do mesmo ano, pune aqueles que corrompiam as filhas-famílias bem dotadas abusando da amizade e parentesco, assim como certos pais e outros parentes que eram cúmplices em "aliciar filhos alheios para entrarem em suas cazas e nellas ter comunicação com as filhas ao fim de (...) os obrigarem a esposar as ditas

\footnotetext{
${ }^{1} \mathrm{O}$ autor também sugere outras leituras nas quais casamentos infelizes realizados nessa base foram o tema favorito de escritores, como, por exemplo, Guimarães Rosa em A história de uma moça rica, e grande parte da literatura produzida por José de Alencar.

2 Ver sobre o tema, especialmente, a parte 1: século XVII, em Nazzari ( 2001, p. 27-82).

${ }^{3}$ A autora cita, em algumas partes, Joaquim José Caetano Pereira e Sousa, Classes dos crimes por ordem sistematica, com as penas correspondentes, segundo a legislação atual, Lisboa, 1816, 2. ed., p. 215/216. Há também descrição de casos ocorridos na Capitania de São Paulo, onde a situação era complicada, uma vez que era habitual os homens se ausentarem por longos períodos; pior ainda a violência com as mulheres quando não havia homem na casa.
} 
filhas" e que, ao se provar legalmente a corrupção, "sendo peões sejam condemnados em dez annos de degredo para as gales: e sendo nobres em outros dez annos para Angola" (COSTA, 1986, p. 409A ). ${ }^{4} \mathrm{O}$ rei pretendia assim "moderar os abusos, e tiranias do poder particular (...) contendo o poder paterno nos seus justos, e razoáveis limites", mesmo porque os "Contractos dos Matrimonios: que dependendo para sua validade de hum reciproco, livre e espontaneo consentimento, se fazião com elle sempre incompativeis a coacção, e a violencia". 5

A Igreja, especialmente os jesuítas, defendia a independência dos filhos na decisão do casamento. No Brasil colônia, o que parece ter sucedido em vários casos foi a mudança de residência dos contraentes de uma capitania para outra, evento não incomum nesse período, "época de grande mobilidade geográfica", conforme documentação para a Capitania de São Paulo em finais do século XVIII (SILVA, 1984, p.119-121) e, devido às dificuldades de comunicação e pela boa vontade dos padres que fechavam os olhos - ou pelo menos um dos olhos - para certas exigências da lgreja, tanto que havia queixas nesse sentido, casavam-se em outras freguesias.

\section{Idade ao casar e diferenças de idade entre os cônjuges}

A proporção entre as idades dos cônjuges é primordial, conforme ensinamento de D. Francisco Manuel de Melo, em sua Carta de Guia de Casados e Adágios, que apregoa tudo sobre a igualdade etária, social, física e moral para um bom casamento (ALMEIDA, 1988/89). Os casamentos desiguais quanto à idade eram usuais nessa época colonial, contrariando as lições dos moralistas de então, enquanto os casamentos desiguais do ponto de vista social ou religioso eram muito malvistos, em todo o Brasil. Essa situação também ensejava desconfiança no que diz respeito ao dote, como se vê adiante, e apresentou resquícios durante o século XX. Mas, como a escolha era dos pais, as igualdades estavam sujeitas aos interesses deles.

Segundo o Direito Romano e o Canônico, a idade ao casar era, em Portugal e no Brasil, de 12 anos para as meninas e 14 para os meninos. As Ordenações foram silentes no que tange a matéria. ${ }^{6}$ Em Portugal e no Brasil, a idade podia ser suprida legalmente em certos casos. Todavia, vigiam em Portugal antes do Concílio, como em outras partes, os esponsais, que podiam ser: a sponsalia de praesente, que era uma verdadeira forma de matrimônio indissolúvel, embora dispensando a assistência do sacerdote; e a sponsalia de futuro, promessas de futuro casamento a ser contraído por pessoas hábeis e desimpedidas, ou seja, maiores de sete anos de idade, e que não era incomum acontecer até antes dos sete anos em Portugal. ${ }^{7}$ Nos países regidos pela common law (Inglaterra e Estados Unidos), o casamento contraído antes dos 12 ou 14 anos valia como esponsais, mas podia ser desfeito antes da puberdade. Segundo Clovis Bevilacqua (1896, p.15-16 e 86), os esponsais seriam uma transformação da anterior compra de mulheres, e a "confirma-

\footnotetext{
${ }^{4}$ A autora traz parte de um auto de divórcio em que o marido dá informações de que foi levado, por aquele que foi seu futuro cunhado, a pousar em casa da família, e pelo mesmo cunhado enganado na ocasião quanto à riqueza da futura esposa.

5 Ambas as leis estão publicadas em Almeida (1870, p. 1.050-1.053). É interessante observar que a preocupação de "pai" dos reis com seus súditos, aliás expressa no texto da lei, compreensível àquela época, se estendeu para o Direito Eclesiástico e chega até nós no século XXI, quando o Estado se arvora no direito de interferir em aspectos da vida privada das pessoas, que são hoje, muitas vezes, direitos personalíssimos.

${ }^{6}$ Bevilacqua (1896, p. 86) e Teixeira de Freitas (1865, notas ao art. 81) observam que "pelo direito canônico (Constituições do Arcebispado..., livro 1ำ, tit. 63 n. 262 e tit. 64 n. 267) eram essas as idades estipuladas, mas poderá o Juiz dos Órfãos suprir o consentimento ou conceder licença de casamento de menores impúberes, com consentimento dos pais ou tutores?" Para ele a solução é negativa, mas como se choca com o direito canônico, daí o silêncio da lei.

7 Segundo Teixeira de Freitas (1865, p.87-88)), em comentários ao artigo 76, os esponsais eram regulados pelo livro 3 , título 59 §§ 11 e 21 das Ordenações, tendo sido derrogados pela lei de 1784, que deu nova regulação para a solenidade. Entre nós, diz ele, não é usado, e a escritura se faz por ocasião do pacto antenupcial, quando os contraentes excetuam ou declaram o regime da comunhão legal.
} 
ção do compromisso futuro materialisava-se pela dação de arrhas ou pela simples troca de anneis".

\section{Século XIX até a Constituição brasileira de 1988}

\section{Namoro, noivado}

Uma das mudanças mais sensíveis no que tange a organização e o funcionamento da família no Brasil é a que se apresenta para a escolha dos cônjuges. Na nossa sociedade em geral, mas particularmente nas classes abastadas, a escolha do marido para a filha era do pater familias, algumas vezes com a colaboração da mãe da moça. No século XIX, essa escolha foi se modificando, tendo os interessados uma voz mais ativa.

Precediam o noivado propriamente dito duas a três fases: troca dos primeiros e furtivos sinais de interesse recíproco e da exploração das possibilidades de aproximação e de comunicação interpessoal direta e próxima; associação deliberada ou namoro em sentido exato; e compromisso preliminar ao noivado formal, também dito oficial. Assim se estruturava o padrão tradicional de namoro, denominação que Azevedo (1986, p.9) utiliza para distingui-lo de modalidades mais recentes.

Pelo art. 209 do Projeto Bevilacqua do Código Civil, eram nulas as penas convencionais estabelecidas para o caso de rompimento do compromisso esponsalício (apud ESPÍNOLA, 2001, p.36-37, nota 78). ${ }^{8}$ Todavia, o art. 210 dizia: "se o compromisso de casamento constar da publicação de proclamas, regularmente feita, o promitente arrependido, sem culpa do outro, deve indenizar este último das despesas feitas em atenção ao casamento ajustado".

O namoro era secreto e se desenrolava na janela, na porta, no portão, mas não dentro de casa, e sob a vigilância constante de algum membro da família, para que não fosse comprometida a fama das jovens. O assunto namoro e os relativos a sexo não eram mencionados em família, nem o namorado era admitido em casa dos pais da moça. O controle familiar era exercido pelo pai, pela mãe e por outros parentes ou agregados residentes, sendo que os irmãos assumiam a obrigação de "defender" as irmãs de namorados julgados mal-intencionados, muitas vezes até os atacando fisicamente (AZEVEDO, 1961, p.221). Após o pedido formal, quando se iniciava o noivado oficial, a vigilância continuava, porém mais discreta e com certas liberdades, como poder o par se encontrar em público.

Segundo Thales surge mais tarde um novo modelo de namoro e noivado, ainda preso a padrões e tradições familiares patriarcais, derivado da revolução sexual que ocorreu em fins do século XVIII na Europa, e que se desenrolava também fora de casa e começava a ter um sentido mais afetivo, substituindo o antigo padrão pelas exigências do amor romântico e do casamento por amor. A felicidade dos casais vai deixando de se subordinar unicamente aos interesses familiares, apesar de a vigilância não dar tréguas, não se permitindo aos noivos ficarem sós, devendo sempre estar acompanhados por um chaperon, em geral irmãos menores, tias e outros. Esses, segundo Thales de Azevedo (1986), eram também ditos alcoviteiros, onze letras. ${ }^{9}$

Thales de Azevedo também se refere ao padrão dito tradicional no início do século XX, variante dos costumes europeus encontrados nos estratos de melhores condições sociais e econômicas, que começou a se estruturar no século XIX nas cidades brasileiras, com a iluminação com lampião de gás, e bem mais tarde nas maiores cidades com a eletricidade e outras novidades

\footnotetext{
8 Nessa mesma nota, Espínola observa que Clovis Bevilacqua, após a supressão dos artigos na Câmara, escreve "a promessa de casamento existe e existirá sempre, porque antes do casamento ser celebrado é preciso que o noivo se dirija à noiva, ou a sua família, e ajuste casar-se". E estabelecido o noivado, chamados contratos estabelecidos pela fé da honra, na Colômbia, se efetuam despesas extraordinárias, tendo em vista exclusivamente o enlace projetado, donde decorre o direito material de ressarcimento de danos.

9 A ação de "tomar conta" dos noivos, favorecendo o namoro, recebia vários nomes. Por exemplo, em São Paulo, diziase segurar vela, ser pau de cabeleira. Azevedo (1986, p.29-30 e. 84-87) cita ainda, na Bahia, ser pau de cabeleira, ser cocada, segurar vela e, no Rio Grande do Sul, dôce-de-pera.
} 
tecnológicas, liberando a mulher do trabalho pesado diário. Nessa época, tiveram papel importante as carruagens, o teatro lírico, os jornais, os bailes, os sobrados e solares; os senhores de engenho e a crescente importância do comerciante e dos homens de governo.

O padrão "moderno" de namoro - o colóquio intimista e, bem mais para frente, a paquera -, que funcionava entre as camadas mais abastadas da sociedade, mas que influenciava as menos favorecidas, veio a ser acentuado com a crise nos costumes instalada depois da Segunda Guerra e com a divulgação ocasionada pelo rádio, cinema, por viagens, pelo contato com outros povos e costumes, pelo modo de vida urbano mundial, causando grandes conflitos familiares na sociedade brasileira, devido aos padrões tradicionais ainda em voga, especialmente no rosário de vilas e cidades pequenas espalhadas pelo interior do país.

Adiante, o "flirt", "a institucionalização do 'footing' (...) nas ruas, nas praças, em todas as capitais brasileiras - de Fortaleza a Porto Alegre, nas ruas do comércio chic de modas, nas sorveterias, nos cafés ou nos jardins, a freqüência às matinées, ao teatro, modistas, dentistas," o telefone e o automóvel foram um marco na transformação do namoro mais antigo, tornando a iniciativa no casamento assunto mais ligado às partes interessadas do que aos pais dos pretendentes, uma vez que diminuía a importância da grande parentela (AZEVEDO, 1986, p. 71-76; MELLO E SOUZA, 1951, p. 308). A verdade afetiva nos séculos XVII e $\mathrm{XVIII}$, pregada pela literatura, estava ligada ao racional; já na literatura do século XIX, com Stendhal, nasce o amor-paixão, o carinho, a atenção, cuja verdade afetiva se encontra no fundo do coração e que é muito mais do que a verdade racional.

Nos vários estados brasileiros, algumas famílias das classes abastadas, tanto no meio urbano quanto no rural, "feridas em sua honra, tomam medidas extremas para segregar as filhas [quando homens que tinham relações com namorada e noiva rompessem o compromisso] num reformatório que é, antes, uma prisão perpétua, convento de religiosas dedicadas a 'regeneração das moças perdidas ou desviadas'”, e era preciso muito prestígio para conseguir vagas tanto no Brasil como em Portugal (AZEVEDO, 1986, p.71). ${ }^{10}$ Nesse estrato social, que afinal imprime como padrão sexual a castidade, a mulher que houvesse perdido sua virgindade e não conseguisse manter isso em segredo "tinha somente três alternativas: prostituição, discreta ou, se fosse pobre, declarada; celibatarismo; ou um casamento arranjado" (MELLO E SOUZA, 1951, p. 309).

Para a população dos estratos socioeconômicos mais baixos na zona rural e vilas, não se tem a família-grande como padrão particularmente desejável nem a sua solidariedade característica, e a virgindade feminina, apesar de teoricamente ser o padrão desejável, não era condição que impedisse a união estável ou o concubinato e, consequentemente, as normas de vigilância e segregação dos sexos não tinham a elaboração encontrada nas classes mais ricas e médias, para as pessoas que viviam tanto na zona rural como na urbana, e as uniões concubinárias eram aceitas pelo costume e pela tradição (WILLEMS, 1954, p. 337; AZEVEDO, 1961, p. 223-224).

O amor e o carinho eram aspectos relevantes das uniões dos pobres e libertos, enquanto em outros estratos sociais apareciam como consequência da vida cotidiana. Eni Samara (1984, p.103) refere-se ao fato de que, nos casamentos dos primeiros, os padrões de moralidade eram mais flexíveis, e quase não havia bens a dividir ou oferecer; talvez por isso essas uniões eram mais facilmente desfeitas, pois, esmaecendo o estímulo inicial, não havia razões no plano pessoal para preservá-las e, no plano social, a separação ou um novo concubinato não apresentavam graves consequências. ${ }^{11}$

\footnotetext{
10 Ver a preciosa descrição dos acontecimentos relativos a essa dificuldade, nas notas das páginas 72 e 73 dessa obra de Azevedo.

${ }^{11}$ A autora relata as memórias do conselheiro José Barbosa de Oliveira sobre como ocorreu seu compromisso matrimonial, na São Paulo de 1847, quando foi levado por uma pessoa influente à casa de seu tio, para pedir a mão e conhecer sua futura esposa.
} 
Observa-se que o plano jurídico relativo ao concubinato, o tratamento normativo fundado na vida social das classes abastadas, não se adaptava a essa outra realidade sociológica, restringindo-se, no caso, a um formalismo vazio, sem a função social e jurídica pretendida pelo ordenamento.

O defloramento e crimes como a sedução e o estupro, que não eram incomuns no tempo do namoro, foram, o primeiro, enquadrado como ilícito civil (na Consolidação) e pelo art. 183, inciso IV, do Código Civil de 1916, enquanto os outros dois, no Código Penal, apesar de que distinguir sedução de certos tipos de "estupro" não seja uma questão de fácil solução. O que se percebe nesse item é que o crime não era tanto a violência física em relação à vítima, como foi mencionado por vários pesquisadores, mas a violência "moral" ao pai da vítima, cuja honra (e da família toda) residia no órgão sexual feminino. Assim, no caso masculino, se o crime fosse de sedução, a pena era indenizatória; e de prisão, se o estupro (sedução) fosse por violência e rapto.

Seria interessante conhecer como os crimes passados - sedução por estupro, adultério e bigamia - foram normatizados como ilícito penal. Como era realizada essa escolha? Quem seduz quem? Parece terem sido os costumes religiosos, ou seja, derivados da pregação da Igreja Católica, que definiram quais pecados eram os mais graves. Nos crimes contra os costumes, é valorizada a mulher "honesta", na medida em que o Código, "ao punir a posse sexual mediante fraude, o rapto e a sedução, valoriza a virgindade e a monogamia. Para os homens é valorizada a liberdade sexual. Já o estupro é classificado como crime contra a liberdade sexual, em vez de ser considerado contra a pessoa, como agressão física e também moral" (BARSTED, 1987, p. 108). O Código Penal, articulado com o inciso IV do art. 183 do Código Civil de 1916, pune o erro essencial, que prevê a nulidade do casamento se o marido constatar a nãovirgindade da noiva.

O tabu da virgindade da mulher, impedimento dirimente relativo a erro de pessoa desde as Constituições Primeiras do Arcebispado da Bahia, ainda deixa resquícios no correr do século $X X$, e não só na zona rural. Thales de Azevedo (1986, p.71, nota 8) traz um julgado de anulação de casamento por desvirginamento na cidade do Rio de Janeiro, datado de $1969,{ }^{12}$ que evidencia a força do costume tornado lei pelo Código Civil de 1916, que veio sendo gestada a partir da segunda metade do século XIX.

Esse mesmo autor conta que, uma vez tendo ocorrido o desvirginamento, restam ao "culpado" duas alternativas: casar "a pulso" ou casar às pressas, antes que estoure o escândalo, não sendo "raro que o culpado seja obrigado, por sentença judicial, a pagar um dote à prejudicada". Embora esse tipo de indenização não seja comum nos dias de hoje, cita a seguinte notícia publicada no jornal $A$ Tarde (Salvador, 16/12/72): "Fato inédito na Justiça bahiana ocorreu na 10a Vara Cível cujo Juiz condenou $\mathrm{X}$ ao pagamento da multa de vinte mil cruzeiros por haver seduzido - e não casado - sua noiva" (AZEVEDO, 1986, p.73-74)."

Os arts. 219, inciso IV, Código Civil de 1916, e art. 1.786, § 1ㅇ, prescreviam a ação anulatória do defloramento em dez dias a contar da data do casamento. A Lei n. 13, de 29 de janeiro de 1935, que dispunha sobre o termo inicial dessa prescrição, foi revogada pelo Decreto-lei n. 5.059, de 8 de dezembro de 1942. Essa atitude está tão arraigada no povo brasileiro que, em 1 으 de

\footnotetext{
12 O autor transcreve: "Em 12 de novembro de 1969 o Tribunal de Justiça do então Estado da Guanabara, em acórdão unânime de sua 1. - Câmara Civil, decidia a respeito da Apelação 66.679 que 'se a ré confessa o defloramento anterior às núpcias por outro homem que não aquele com quem se casou e a prova pericial confirma o desvirginamento antigo, é de ser declarado nulo o casamento, por erro sobre a pessoa do outro cônjuge. O fato de ser a mulher honesta não obsta a procedência do pedido'. No comentário do relator da sentença, lê-se: '(...) vivemos num agrupamento societário onde, para muitos, a honra do varão e os destinos do casamento repousam no hímen feminino. No momento em que o homem atinge a Lua, ainda raciocinamos em termos de carros de bois'." (AZEVEDO, 1986, p.71, nota 8).
} 
maio de 2005, o então presidente da Câmara dos Deputados, ${ }^{13}$ digno representante do pensamento popular, declara em entrevista: "a mulher deve se casar virgem (...) e o homem nem tanto". Esse "nem tanto" é uma maneira de disfarçar - ou de escancarar? - o pensamento masculino, baseado na dupla moral sexual ainda em voga.

Emílio Willems (1954, p.330, nota 3, e p. 337) chama a atenção para as provisões do Código Penal brasileiro quanto aos "crimes contra a liberdade sexual" que refletem a valorização da virgindade feminina. Por exemplo, no art. 220, o defloramento ou rapto de mulher "honesta" menor de 21 anos, e mesmo se o defloramento fosse praticado com a anuência dela, poderia acarretar ao homem uma sentença de três anos de prisão. Ou seja, "virtualmente todos os casos de relações sexuais fora do casamento, com mulheres 'honestas' ou 'virgens' menores de 21 anos, podem ser interpretados como defloramento ou sedução".

Ao se referir às famílias das classes mais populares, Willems (1954) diz que a fase preparatória para o casamento, o namoro, é quase inexistente. Após o pretendente ter tido algum entendimento com a moça e tendo obtido o consentimento do futuro sogro, que raramente o nega, e como o arranjo não envolve grandes problemas econômicos, o casamento se realiza em seguida, casandose as moças entre os 14 e os 17 anos.

\section{Idade ao casar e diferenças de idade entre os cônjuges}

As Ordenações, e posteriormente nossas leis, não fixavam a idade em que os menores podiam se casar validamente, porém, a capacidade para casar presumiase aos 12 anos para as meninas e aos 14 para os meninos, idades que marcavam a puberdade entre os romanos e com as quais o Direito Canônico concede-lhes capacidade física e moral para casar. No caso de idades inferiores, era necessário, além da autorização paterna, o suprimento de idade pelo juiz de órfãos, mas não era proibido o casamento, como mostram as promessas de esponsais. No limite superior também podem os velhos de qualquer idade se casar, "ainda que seja dentro do ano do luto" (TRIGO, 2004, p.82-83). Mas não foi sempre assim, nem os costumes, nem a lei, ambos variando com a época em foco.

Pelo Direito de Justiniano, a idade legal da puberdade (pubes) do homem estava fixada aos 14 anos e aos 12 a nubilidade feminina (nubilis, viripotens), associando-se desde então a nubilidade à puberdade. A lei romana também estipulava a idade máxima permitida para casar, e a Lei Papia Popaea proibia o sacramento do matrimônio à muIher com 50 anos completos e ao homem maior de 60. O Código Canônico de 1917, no que se refere à idade ao casar, alterou-a para 14 e 16 anos, respectivamente, para a mulher e o homem, desligando a puberdade da idade ao casar (FEIGUIN, 1970, p. 74).

As idades para casar de 12 e 14 anos vigiam também na Inglaterra, Espanha, Grécia, Turquia, Hungria católica e Argentina. $\mathrm{Na}$ França, o Código de Napoleão, após muito debate, alterou a idade ao casar de 13 e 15 para 15 e 18 anos, para mulheres e homens, respectivamente, mas sempre com autorização dos pais (FEIGUIN, 1970, p. 74-75). Para a Hungria protestante, Rússia, Romênia e Alemanha, as idades eram 15 e 18 anos, respectivamente, para mulheres e homens, sendo na Suíça 14 e 20/21 e, nos Estados Unidos, 12 e 17/18 anos, também respectivamente (BEVILACQUA, 1896, p. 86).

Como foi visto, até o final do século XIX, ainda eram admitidos os esponsais por escritura pública a partir dos sete anos de idade. Clovis Bevilacqua faz referência ao fato de que o Direito Canônico, pelo Decreto de 2 de agosto de 1907, por ordem de Pio $X$, promulgou pela Sagrada Congregação do Concílio a regulação sobre a matéria dos esponsais. No que se refere ao Brasil, o autor afirma que alguns dos projetos de códigos civis brasileiros mantiveram os esponsais, enquanto outros declararam

\footnotetext{
13 Deputado Severino Cavalvanti, tanto em entrevista publicada nos jornais Folha de S. Paulo e Estado de S. Paulo, entre outros, como transmitida pela rádio, TV e outros meios de comunicação.
} 
o instituto extinto. O Código Civil de 1916 não faz referência alguma a esse instituto e, assim, "Desapparecem, os esponsaes do nosso direito, sem deixar vestígios". ${ }^{14}$

Com o tempo, a argumentação se deslocou do campo fisiológico ou biológico e do comercial, para o social, ou melhor, para o intelectual e moral, predominando a ideia de que o casamento era mais uma união de almas do que apenas de corpos, sendo necessária maturidade de espírito para administrar o lar e educar a prole, além de ser a expressão de consentimento dos nubentes e não da vontade dos pais.

Pelo art. 7으, § 8o, do Decreto n. 181 de 24 de janeiro de 1890, promulgado pelo governo provisório da República, são proibidos de se casarem as mulheres menores de 14 anos e os homens menores de 16 anos, limites esses que definem por lei o casamento válido. $\mathrm{O}$ art. 18 do Capítulo III desse mesmo diploma, sobre as pessoas que podem opor impedimento, reza:

O maior de 16 annos ou a maior de 14 , menores de 21 annos, são obrigados a obter antes do casamento o consentimento de ambos os paes, si forem casados, ou, no caso de divergência entre elles, ao menos o do pae. Si, porém, elles não forem casados, e o contrahente não tiver sido reconhecido pelo pae, na fórma do $\S 1$ 으 do artigo $8^{\circ}$, bastará o consentimento da mãe.

Os artigos mostram que, mesmo que possuam as idades permitidas para casar, são relativamente incapazes, tendo os noivos de obter o consentimento do pai, ou, no caso de este não ser conhecido ou "não existir", o da mãe, indicando o poder absoluto do pai e secundário da mãe sobre os filhos menores de idade, embora a mãe por lei devesse criá-los até pelo menos os três anos de idade. Comenta Orlando Gomes que não é possível deixar de reconhecer que, nos dias de hoje, a maturidade ocorre mais cedo do que na época de nossos avós, todavia, não é possível dizer que "a menor atinge aos 14 anos pleno desenvolvimento espiritual e é capaz de compreender, em todo seu significado, a importância do vínculo matrimonial, mas também não o alcançou, nem o entende, na idade em que o Código vigente permite o casamento, e, não obstante, os que se insurgem contra o Projeto aplaudem o Código" (apud FEIGUIN, 1970, p. 100-101).

O Código Civil de 1916, art. 183, inciso XII, não permite o casamento das mulheres menores de 16 anos e dos homens menores de 18, postergando por dois anos a idade ao casar para os dois sexos, mas mantendo a condição de anulabilidade caso não possuam a autorização do responsável. Ao que parece, o costume antigo era se casarem as jovens entre os 15 e 20 anos, afora alguns casos nas famílias do período colonial, quando se casavam ainda mais jovens.

No século XIX, na cidade de São Paulo, por exemplo, "é pequena a incidência de casais muito jovens: dos 661 casados, apenas 48 (7\%) tinham menos de 20 anos e, desses, 37 ainda não tinham filhos". No recenseamento de 1836, "as idades das esposas variaram de 14 a 89 anos e as dos maridos de 16 a 97" (SAMARA, 1986, p. 79). Em 1827 em São Paulo, de 334 brancos de ambos os sexos, $226(67,6 \%)$ eram solteiros, $85(25,5 \%)$ casados e $23(6,9 \%)$ viúvos (SAMARA, 1984, p.96), indicando a existência de grande número de celibatários, e se a determinação da idade legal visava promover os casamentos desde cedo, provavelmente com o intuito de impedir o concubinato, não era bem acatada, pois não correspondia aos costumes da população nem às condições do mercado matrimonial.

$\mathrm{Na}$ Bahia não era tão incomum conseguir alterar certidões do Registro Civil, a fim de que não ficasse a noiva mais velha do que o noivo (AZEVEDO, 1986, p. 52), o que dificulta a credibilidade de algumas certi-

\footnotetext{
14 Apud Bevilacqua (1917, p. 7) e também Feiguin (1970, p.76), citando Carlos Sampaio, Curso de direito civil: do casamento. São Paulo, Saraiva, 1923, v. 1, p. 213. A autora apresenta, na página 78, uma relação de legislação comparada para 21 países, com as devidas idades mínimas legais ao casar, por volta de 1923; na página 79, uma lista para 24 países em data próxima a 1941; e na página 81, ao redor de 1962. Todas as listagens se iniciam aos 12 anos para mulheres, indo até 21 anos para os homens, sendo que para a Alemanha, em 1962, a idade feminina de 16 anos correspondia à maioridade da mulher.
} 
dões a esse respeito. Em duas paróquias da cidade de Salvador, durante o século XIX, excepcionalmente, os vigários registravam as idades dos nubentes, sendo que a moda de idade dos casamentos "situava-se entre 20 e 29 anos; menos freqüentes, abaixo dos 20 e raros, antes dos 15; os rapazes casavam-se predominantemente dos 20 aos 29 anos, concentração que se torna mais forte a partir dos 25 e se estende com certa freqüência aos 35", sendo que os noivos eram em média cinco anos mais velhos que suas noivas, que vinham para se casar "dos 15 aos 24 anos, e mais particularmente, entre 15 e 19" (ATAÍDE, 1975 apud AZEVEDO, 1986, p.50).

Não se casando entre 25 e 30 anos, a mulher recebia o qualificativo de solteirona, termo com conotação pejorativa, denotando incapacidade de conseguir um casamento, sendo relegada a viver de favor em casa de parentes, assumindo papéis a essa figura destinados - cuidar de sobrinhos, ajudar nas tarefas da casa, meio governante/meio parente pobre -, ou vivendo uma situação também indesejável de concubina ou prostituta. ${ }^{15}$

Em Guaratinguetá, século XVIII, Capitania de São Paulo, 45\% das mulheres eram casadas com homens dez anos mais velhos (HERMANN, 1948 apud NAZZARI, 2001, p. 333, nota 27). ${ }^{16}$ Oracy Nogueira, com dados colhidos no mapa da população de Itapetininga de 1775, encontrou, entre 156 casais livres, $82,7 \%$ em que os homens eram mais velhos ou de mesma idade que suas mulheres e $17,3 \%$ em que as mulheres eram mais velhas do que seus cônjuges. A moda de diferença etária entre os casais era de 10 anos e a média de 11 anos; "em 1955, de 273 casais cujos editais de casamento correram pelos Cartórios do 1 o e do $2^{\circ}$ 은 Subdistritos de Paz de Itapetininga", 83,9\% eram de noivos mais velhos ou de mesma idade que suas noivas, e $16,1 \%$ de noivas mais velhas que os noivos, sendo que a diferença média de idade havia caído para cinco e meio a seis anos, e a modal ficou nos três anos. As moças, no geral, casavam-se com 14 ou 15 anos (NOGUEIRA, 1962, nota de rodapé p. 264-265). Para a mesma época, entre famílias de classe inferior de duas comunidades rurais de São Paulo, as moças se casavam em idades que variavam de 14 a 17 anos (WILLEMS, 1954, p. 337).

Para a área rural de Bofete, no final da década de 1940, a idade mais comum para se casar era de 15 a 16 anos para as muIheres, com limite inferior de 13 e superior de 20 anos, e de 18 a 22 para os homens, sendo que depois dos 30 era difícil arranjar casamento para ambos os sexos (MELLO E SOUZA, 2001, p. 297). Esses relatos evidenciam que a idade legal para casar não era o que contava para a comunidade, que considerava mais importante o casamento religioso, uma vez que, além da solenidade dentro da Igreja, apresentava várias manifestações no trajeto festivo, como, por exemplo, um cortejo a cavalo e a pé pelas ruas da cidade até a Igreja, o que, na área estudada por Antonio Candido, se chamava noivado.

Pesquisa realizada no distrito de São Paulo, em 1965, ${ }^{17}$ registra: $79,8 \%$ das muIheres se casaram até os 25 anos de idade; $15,9 \%$ entre 25 e 29 anos e $4,3 \%$ após os 30 anos. A idade média ao casar foi de 22 anos. Para as mulheres nascidas de 1915 a 1930, a média ao casar sempre ficou ao redor dos 22,5 anos (mas essas mulheres são as sobreviventes das coortes nascidas nesses anos, o que leva a um rejuvenescimento da média de idade ao casar, particularmente pela alta mortalidade das mães em idades

\footnotetext{
15 "As mulheres, no passado como no presente (...) são persuadidas de que não casar é um insucesso. Daí a distinção, na língua inglesa, entre spinster - a rejeitada para o casamento, a nossa solteirona - e bachelor girl - a solteira, que ainda não foi escolhida mas é casável, marriageable" (SCHURMER, 1972 apud AZEVEDO, 1986, p. 51). Esse mesmo autor cita, na página 50, Gilberto Freyre (1968). Ver também sobre o tema Emílio Willems (1954, p. 330).

16 Nazzari (2001, p. 223) cita também o curioso dado de Hermann (1948): "chegou a 14\% o número de mulheres mais velhas casadas com homens mais jovens, sendo que em dois desses casos as esposas eram mais de vinte anos mais velhas".

${ }^{17}$ Foram entrevistadas 1.965 mulheres não-solteiras entre 15 e 49 anos completos, e com apenas uma união, ou seja, coortes de mulheres nascidas desde 1915 a 1950 (apud CAMARGO; BERQUÓ, 1971, p.15 e segs.Ver página 13, tabela 3 , Idade ao casar das mulheres).
} 
muito jovens). Nessa pesquisa, levando em conta apenas as mulheres que tinham mais de uma união e considerando faixas etárias com intervalos de cinco anos, do total de 2.709 casais, $41,6 \%$ tinham suas idades na mesma faixa etária; em $54,5 \%$ o marido estava em uma faixa mais velha do que a mulher - e 38,2\% desses maridos possuíam idades na faixa de cinco anos mais do que as mulheres -; e em 4,2\% a mulher estava em uma faixa etária superior à do marido.

Para a mesma pesquisa, separando os casais segundo a idade da mulher em dois grupos, verifica-se que, entre as 905 mulheres com menos de 30 anos, $1,0 \%$ delas estavam casadas com homens de faixas etárias inferiores, $28,2 \%$ com homens da mesma faixa e $70,8 \%$ com os de faixas superiores. Já para as 1.804 mulheres com 30 anos ou mais, $6,1 \%$ dos maridos estavam em classe etária inferior à delas, $47,6 \%$ encontravamse na mesma faixa etária e $46,3 \%$ em faixas superiores, o que indica, de um lado, que as mulheres mais velhas casavam-se mais com homens mais moços, até porque a mortalidade masculina sempre foi mais elevada, e, de outro, uma tendência para a diminuição do intervalo de idade entre os cônjuges, ou seja, delineia-se um padrão mais parecido com as recomendações de D. Francisco Manuel de Mello em seu manual, e que é cada vez mais comum no país, assumindo uma característica "moderna".

Jorge A. Frias (1941 apud FEIGUIN, 1970 , p. 74) assim se expressa: "o direito moderno não estabeleceu um limite máximo de idade [para casar], a velhice e a desproporção de idade entre os esposos não constitui impedimentos". Mas o Estado vem impedindo as pessoas mais velhas, desde o Código Civil de 1916, em seu inciso II do parágrafo único do art. 258, de escolher o regime de bens, obrigando as mulheres maiores de 50 anos e os homens maiores de 60 a se casarem pelo regime da separação total de bens. Não será isso resquício da Lei Papia Popaea, que não permitia o matrimônio de pessoas com essas mesmas idades? Ao tornar essas pessoas incapazes, joga-se na lata do lixo a "vontade livre", fundamento do matrimônio e também do Direito.
Nos 20 anos que vão de 1960 a 1980, observa-se que as mulheres, em média, casavam-se entre os 22 e os 23 anos e os homens, entre 25 e 26 . O celibato foi menor entre os homens, ficando entre $6 \%$ e $7 \%$ e, para as mulheres, entre 8\% e 9\% (BERQUÓ, 1989, p. 9).

\section{Pós-Constituição de 1988 até o século XXI}

Namoro, noivado

As mudanças nos costumes e na relação entre os sexos foram ocasionadas especialmente, mas não só, pela possibilidade efetiva de separar a relação sexual da procriação; pelos efeitos das alterações das regras e normas que regiam a escolha dos cônjuges, modificando a forma de namorar e também noivar; pela valorização da pessoa e das relações de afeto a partir da segunda metade do século XX; pelos direitos da personalidade; enfim, pela importância da dignidade humana elevada a princípio constitucional em 1988. O noivado, com o formato como era conhecido no passado, que envolvia o pedido da mão da noiva ao pai dela, feito pelo pai do noivo, advindo dos costumes romanos, praticamente já não subsiste. Às vezes deparamos, em geral nas classes abastadas, com o costume de o futuro noivo pedir a mão da namorada ao pai dela; porém, o mais usual é os noivos comunicarem aos pais sua decisão de se casarem ou morarem juntos.

O namoro se mantém, mas bastante diferente do que era no passado recente, isto é, até os anos 1970 nas classes elitizadas da sociedade; nos outros estratos, e particularmente nas cidades pequenas, ainda se cultua um namoro mais tradicional entre os jovens, mas diverso das décadas anteriores. É evidente o papel que a escola, a escolaridade, a mídia em geral, especialmente a TV por meio das novelas com sua grande divulgação por esse Brasil afora, e mais recentemente $o$ acesso à Internet tiveram e têm na construção de novas formas de os jovens se relacionarem, mas também influenciam as formas de relacionamento entre os não tão jovens. 
Pode-se dizer que, atualmente, certo tipo de namoro não difere muito das uniões conjugais que eram chamadas de mancebia, amasia, concubinato, etc. nos séculos anteriores; e nem se pode dizer que são relações eventuais, sem compromisso, do tipo "amizade-colorida" de algumas décadas atrás, ou as de que hoje se diz "ficar". Contudo, do "ficar", muitas vezes, evolui-se para a denominada "escalada do afeto" (OLIVEIRA, 2006), podendo transformar-se no "rolo", passando ao final à união estável ou ao casamento, ampliando a responsabilidade jurídica, que nesses casos não se restringe apenas à hipótese de gravidez. $\mathrm{Da}$ presença de filho decorrem responsabilidades maternais e paternais, que se encontram previstas no Estatuto da Criança e do Adolescente, Lei n. 8.069, de 13 de julho de 1990 , arts. 19 a $24 .{ }^{18}$

O namoro de hoje, em geral, tem seu fundamento em uma relação afetiva, amorosa, no companheirismo e implica compromisso entre os partícipes, podendo mesmo existir coabitação entre eles, mas não obrigatoriamente existe a intenção de constituir família. Isso poderá ou não acontecer, com esse ou outro parceiro, mais para a frente.

Os requisitos do namoro atual, como compromisso sério, relação de certa duração temporal, auxílio mútuo, viver sob o mesmo teto, dividir a mesma cama, frequentar as famílias recíprocas, tiveram uma tentativa de serem transformados e engessados em união estável pelas leis de 1994 e 1996. Alguns casais, para se defenderem da legislação, findam por estabelecer o "contrato de namoro", a fim de que as regras estipuladas para a união estável quanto a patrimônio e sucessão não vigissem para esses casos. Todavia, esse pacto pode ter sua validade questionada juridicamente, pois ainda não houve tempo para se ter uma jurisprudência firmada (DAL COL, 2004, p. 140 e segs.), e como a união estável é um fato jurídico e comprova-se pela convivência mos uxorius, não adianta, nesses casos, mudar o rótulo para namoro. No geral, o que importa para o Direito é o fato com suas consequências jurídicas, mas essa mudança nos costumes, nas atitudes e mentalidade das pessoas está a exigir uma transformação nos princípios do Direito de Família que regem o namoro e o diferencia das uniões conjugais.

Contudo, existem alguns julgados, como o acórdão do TJRS:19 "Demonstrado que antes de coabitarem por curto espaço de tempo, as partes viviam com seus pais, e sua relação era de simples namoro, não se implementa o convívio constitucional, inexistindo prole ou prova de contribuição para o cabedal no dissídio", evidenciando que não é caso de ser considerada união estável só pela presença de relações sexuais, convivência familiar, quando existentes na situação de namoro. Outro acórdão do mesmo Tribunal explicita: "O namoro prolongado, mesmo em congresso íntimo, desenrolado enquanto as partes resolviam anteriores casamentos, não induz união estável".

É tempo de se pensar em como qualificar certos fatos que podem ter no presente outras conotações e finalidades, que não faziam parte nem dos costumes, nem de legislação anterior. O significado do namoro na vida de certos segmentos sociais precisaria ser repensado para que se faça justiça ao desejo das partes envolvidas.

\section{Idade ao casar, diferenças de idade entre marido e mulher}

A idade média ao casar foi se tornando cada vez mais tardia e, embora os casamentos venham se iniciando em idades muito jovens, ocorrem também em idades mais

\footnotetext{
18 RESP, n. 557.365 - RO(2003/0105996-8), do STJ - Rel. Min. Nancy Andrighi, em que foi dado provimento por unanimidade, ao recurso em ação de investigação de paternidade, no qual "a existência de relacionamento casual, hábito hodierno que parte do simples 'ficar', relação fugaz, de apenas um encontro, mas que pode garantir a concepção, dada a forte dissolução que opera entre o envolvimento amoroso e o contato sexual". Brasília, (DF), 7 de abril de 2005 (data do julgamento).

19 TJRS, AC 599152105, 7aㅡ C.Civ., Rel. Des. José Carlos Teixeira Giorgis, j. 19.05.1999. Na mesma Câmara e com o mesmo relator, AC 598232684 de 2/12/1998. Ambos podem ser encontrados In: Ementário de Jurisprudência, RBDF, 23:157-158, abr./maio 2004.
} 
velhas, o que não era usual no passado. As diferenças de idade entre os cônjuges foi se aproximando, embora continue havendo casos em que elas apresentem certa amplitude.

Até a promulgação e posterior vigência do novo Código Civil, em 2003, Lei n. 10.406 de 10 de janeiro de 2002, a idade legal para se casar era de 16 anos para as moças e 18 para os moços, sempre implicando a autorização dos pais, segundo os arts. 183, XII e 185, do Código Civil de 1916. Dados atuais do Registro Civil mostram que jovens dos dois sexos casam-se bem antes da idade legal: crianças de 11 anos, e até de dez no caso de meninas. Os dados de 2002 para o Brasil, consolidados com base nos registros civis dos estados, mostram que 75.580 jovens entre 10 e 14 anos casaramse, sendo que dois terços deles vivem na zona urbana. ${ }^{20}$ Esse é um costume que era muito comum na zona rural, mas é novo nas cidades, uma vez que o intenso fluxo migratório rural/urbano neste país fazia com que os casamentos na zona urbana fossem mais tardios.

Há uma tendência de diminuição no número de casamentos civis nessas idades muito jovens: por exemplo, pelos dados do Registro Civil do Estado de São Paulo, casaram-se 1.970 meninas até 16 anos em 1993 e, em 2003, foram 401 apenas, representando, nesses dez anos, uma diminuição relativa de $79 \%$; quanto aos meninos, foram 687 casamentos em 1993 até os 18 anos, passando para $580 \mathrm{em} 2003$, o que mostra uma redução de $5,6 \%$, bem menor do que aquela correspondente ao sexo feminino. $\mathrm{O}$ que se viu foi um aumento das uniões informais.

As idades exatas da capacidade legal para contrair o casamento só foram alteradas em 2002, ficando em 16 anos para ambos os sexos (art. 1.517 do novo Código Civil brasileiro), podendo o casa- mento ser anulado caso não tenha havido autorização dos pais. Ou seja, do ponto de vista jurídico, de maneira autônoma, as pessoas só poderiam casar-se ao atingirem a maioridade legal, que era de 21 anos e, em 2002, foi antecipada para os 18 anos. O art. 183, XII, do Código Civil de 1916, não permitia o casamento de mulheres de 16 e homens de 18 anos sem autorização dos pais ou responsáveis, podendo ele ser anulado por defeito de idade, conforme o art. 209 combinado com o art. 183, IX e XII. Contudo, os dados tabulados mostram que muitas pessoas se casavam no civil antes de estarem capacitadas legalmente.

Excepcionalmente, o art. 1.520 do novo Código Civil permite o casamento de quem não alcançou a idade estipulada no art. 1.517, em duas circunstâncias: "evitar imposição ou cumprimento de pena criminal ou em caso de gravidez", o que equivale ao anterior art. 214, no que se refere ao aspecto criminal; o art. 215 anterior dizia "por defeito de idade não se anulará o casamento de que resultou gravidez", indicando de uma certa forma, em 2002, a mesma proteção que existia na norma legal anterior, favorecendo o casamento, caso a mulher - porque é da mulher que se trata - estiver grávida e não tiver ainda completado a idade núbil legal.

No Estado de São Paulo, a idade média ao casar, em 1993, era de 23,97 anos para noivas e 27,08 para noivos e, em 2003 , passou para 26,48 e 29,56 anos, respectivamente, com um aumento de cerca de três anos e meio para mulheres e dois e meio para homens, o que indica uma aproximação da idade entre os cônjuges, também verificada na comparação com outros estudos.

A maior frequência de casamentos segundo a idade, ou seja, a idade modal, de 1993 a 2003, foi sempre para o sexo feminino aos 21 anos; já para o sexo masculino houve uma tendência de aumento, iniciando-se aos 23 anos, em 1993, e gradualmente chegan-

\footnotetext{
20 Para o Estado de São Paulo, onde praticamente não há sub-registro, as médias de idade foram calculadas com base nas tabelas de dados do Registro Civil sobre casamentos segundo a idade dos cônjuges, de 1993 a 2003 , fornecidas pela Fundação Seade (Sistema Estadual de Análise de Dados). Já os dados de 2002 para o Brasil, relativos aos Registros Civis de cada estado, são consolidados pelo IBGE; mas nem todos os cartórios desses estados têm registros confiáveis e, mesmo os que os têm, nem sempre enviam seus mapas a tempo de serem computados nas estatísticas oficiais do IBGE.
} 
do aos 25 anos, em 2003, ${ }^{21}$ acompanhando o envelhecimento da idade ao casar expresso pelas médias populacionais. A duração média dos casamentos dos brasileiros, em 2002, foi de 10,5 anos, variando bastante segundo os estados e regiões. ${ }^{22}$

Dados anuais por grupos quinquenais de idade, para o Estado de São Paulo, mostram que a proporção de mulheres com idade inferior à do marido variou de $70,4 \%$, em 1993, para 69,8\%, em 2003, verificandose uma tendência de diminuição a partir de 2000. A porcentagem de mulheres mais velhas do que seus maridos, sempre próxima a 20,5\%, a partir de 1999 começou a crescer e atingiu 22,2\% em 2003, mostrando um aumento do número de casamento de mulheres mais velhas do que seus maridos (situação que no século $X X$ não era bem-vista em determinadas camadas da sociedade), à custa de uma diminuição no grupo de mulheres mais jovens do que os maridos. No período, para casais com idades iguais, a porcentagem manteve-se estável, ao redor de $8 \% .23$

Observa-se, portanto, que, apesar da maior frequência de casamentos de mulheres mais jovens com homens mais velhos, sempre existiram, em todas as combinações entre faixas etárias, casamentos entre muIheres mais velhas e homens mais jovens, só variando sua proporção. Entre nós, até os dias atuais, tanto a Igreja como o Estado se mantiveram silentes quanto a impedimentos para o casamento com relação às diferenças de idade, respeitando os costumes, possivelmente porque, dada a sua variabilidade, há grandes chances de a norma "não pegar". Observa-se também, por esses dados do Registro Civil, que há casamentos tanto de homens como de mulheres maiores de 80 anos e até de mais de 90 , o que reforça a afetividade e o companheirismo como fundamento do casamento, e tende a aumentar o número desses casamentos no futuro.

Contudo, no Código Civil brasileiro de 2002, inciso II, art. 1.641, é mantida a restrição quanto à escolha do regime de bens, porém, agora, para os maiores de 60 anos, independente de sexo, e por incrível que pareça, com a justificativa da igualdade entre eles. Como só é lícito casarem-se no regime de separação total de bens, estão também impedidos de fazerem doações um ao outro. ${ }^{24}$ Isso é mais uma violência perpetrada aos chamados "idosos", em favor do controle do seu patrimônio por outras pessoas que não os próprios. Transformar os maiores de 60 anos em incapazes de manifestar livremente sua vontade é inacreditável!

Esse dispositivo, segundo Euclides Benedito de Oliveira (2000, p.78), não apenas vai contra o mandamento constitucional de proteção aos direitos de liberdade e igualdade presentes no art. 5으 da Constituição de 1988, mas também "ofende a regra da capacidade das pessoas, constituindo-se em inadmissível capitis deminutio." O autor menciona também Silvio Rodrigues que, ao se referir a essa questão, utiliza a expressão "Tutela excessiva do Estado, sobre pessoa capaz".

Essa situação também é pouco edificante ao se pensar no aumento da longevidade ou esperança de vida e no atual envelhecimento da população brasileira, hoje com mais de 14 milhões de cidadãos com mais de 60 anos. Essa norma deveria rapidamente ser alterada, mas, finda-se por apelar para a criatividade e o bom senso dos doutrinadores e dos administradores do Direito, a fim de construírem uma jurisprudência mais sensata, até que se altere a lei.

\footnotetext{
21 Dados consolidados dos Cartórios do Registro Civil do Estado de São Paulo. Os cálculos são da autora.

22 Disponível em: <http://www.ibge.gov.br/home/presidencia/noticias/noticia_visualiza.php?id_noticia= 132\&id_ pagina $=1>$.

23 Dados consolidados dos Cartórios do Registro Civil do Estado de São Paulo, já citados.

24 Veja-se, por exemplo, decisão em sede de apelação da 2ª Câmara do TJSP - Ap. Civil no 007.512-4/2, Rel. Des. César Peluzo, j.18-08-1998, sobre casamento de maior de 60 anos e doação de bens para o cônjuge, condição não permitida pelo art. 1.641 aos concubinos, e que segundo o relator reflete um quadro de referências sociais de outra época, produto de "autêntica ficção jurídico-normativa (...) que não incide nos fatos em causa, não tendo sido recepcionado pela atual Constituição" (apud OLIVEIRA, 2000, p.78).
} 


\section{Referências}

ALMEIDA, A. M. de. Notas sobre a família no Brasil. In: ALMEIDA, A. M. de (Org.). Pensando a família no Brasil - da colônia à modernidade. Rio de Janeiro: Espaço e Tempo/UFRRJ, 1987, p. 53-66.

Os manuais portugueses de casamento dos séculos XVI e XVII. Revista Brasileira de História, São Paulo, ANPUH/ Marco Zero, v. 19, n. 17, p.191-207, set. 1988/fev. 1989.

ALMEIDA, C. M. de. Código Filipino ou Ordenações e Leis do Reino de Portugal recompiladas por mandado d'el-rei a Filipe I. 14. ed. Rio de Janeiro: Typographia do Instituto Philomathico, 1870; sendo a primeira de 1603, e a nona de Coimbra, de 1824.

ALMEIDA, F. H. M. de. Ordenações filipinas. São Paulo, v. 1, 1957.

ALTMANN, A. M. G.; FERREIRA, C. E. de C. Evolução do censo demográfico e registro civil como fonte de dados para a análise da fecundidade e mortalidade no Brasil. São Paulo: Fundação Seade, 1979.

AZEVEDO, T. de. As regras do namoro à antiga. São Paulo: Ática, 1986 (Ensaios, 118).

Família, casamento e divórcio no Brasil. (Reprint of) Journal of InterAmerican Studies, III (2): 213-237, 1961, tradução de Agnes Toward.

BARSTED, L. L. Permanência ou mudança? Discurso legal sobre a família. In: ALMEIDA, A. M. de (Org.). Pensando a família no Brasil - da colônia à modernidade. Rio de Janeiro: Espaço e Tempo/UFRRJ, 1987, p. 103-113.

BERQUÓ, E. A família no século XXI: um enfoque demográfico. Revista Brasileira de Estudos de População, v. 6, n. 2, p. 1-16, jul./dez. 1989.

BEVILACQUA, C. Código Civil commentado. Rio de Janeiro: Livraria Francisco Alves, v. II, 1917.

Direito da família. Recife: Ramiro M. Costa \& Cia. Editores, Livraria Contemporânea, 1896.
Direito de família. (Ed. rev. e ampliada e adaptada ao Código Civil). Rio de Janeiro: Freitas Bastos,1933.

CAMARGO, C. P. F. de; BERQUÓ, E. S. (Orgs.). Diferenciais de fertilidade. São Paulo: Cebrap, Caderno 1, 1971.

COSTA, R. R. L. D. da. Divórcio e anulação do matrimônio em São Paulo colonial. Tese (mestrado). São Paulo, Departamento de História, FFLCH/USP, 1986.

DAL COL, H. M. União estável e contratos de namoro no NCCB. Revista Brasileira de Direito de Família, n. 23, p. 126-158, abr./ maio 2004

ESPÍNOLA, E. A família no direito civil brasileiro (Co.1954). Campinas: Bookseller, 2001.

FEIGUIN, D. Normas jurídicas e fertilidade no Brasil. São Paulo: Cedip/Faculdade de Saúde Pública/USP, 1970 (Relatório Fapesp). Mimeografado.

LÉVI-STRAUSS, C. Social structure. In: KROEBER, A. L. Anthropology today. Chicago: University of Chicago Press, 1954, p. 524-553.

Structural antropology. New York: Doubleday \& Company Inc., Anchor Books, 1967.

MELLO E SOUZA, A. C. de. The brazilian family. In: SMITH, T. L.; MARCHANT, A. N. de A. Brazil portrait of half a continent. New York: Dryden Press, 1951, p. 291-312 (The Dryden Press sociology publications).

Os parceiros do Rio Bonito. (Co. 1957). São Paulo: Liv. Duas Cidades/Ed. 34, 2001 (Coleção Espírito Crítico).

NAZZARI, M. S. O desaparecimento do dote: mulheres, famílias e mudança social em São Paulo, Brasil, 1600-1900. Tradução de Lólio Lourenço de Oliveira. São Paulo: Cia. das Letras, 2001.

NOGUEIRA, O. Família e comunidade (Um estudo sociológico de Itapetininga). São Paulo: Instituto Nacional de Estudos 
Pedagógicos (Inep), Ministério da Educação e Cultura, 1962 (Coleção O Brasil Provinciano).

OLIVEIRA, E. B. de. Efeitos materiais da separação judicial e do divórcio. In: PEREIRA, R. da C. (Coord.). A família na travessia do milênio. Anais do Il Congresso do IBDFAM, Belo Horizonte, 2000, p. 71-92.

A escalada do afeto no Direito de Família: ficar, namorar, conviver, casar. In: CONGRESSO BRASILEIRO DE DIREITO DE FAMÍLIA, 5ㅇ. Anais... Belo Horizonte, IBDFAM, 2006, p. 315-146.

SAMARA, E. de M. As mulheres, o poder e a família. São Paulo, século XIX. Tese (doutorado). São Paulo: AMPUH/Marco Zero/Fapesp, 1984.

A família brasileira. São Paulo:

Brasiliense, 1983.
SILVA, M. B. N. da. Sistema de casamento no Brasil colonial. São Paulo: T.A. Queiroz/ Edusp, 1984.

TEIXEIRA DE FREITAS, A. Consolidação das leis civis. Rio de Janeiro: Typographia Universal Laemmert, 1865.

Consolidação das leis civis. Brasília, Ed. Fac Símile, 2003.

TRIGO, L. L. Instituições de direito civil brasileiro, (Co. 1857) v. 1, Ed.fac-sim. Brasília: Senado Federal, Conselho Editorial: Superior Tribunal de Justiça, 2004.

WILLEMS, E. A estrutura da família brasileira. Sociologia, São Paulo, 16(4):327-340, out. 1954. (Traduzido pelo próprio autor, de Social Forces, n. 4, maio, 1953.).

\section{Resumen}

La elección del cónyuge

Enfocando los tópicos noviazgo y compromiso, edad al casarse y diferencias de edad entre los cónyuges, este artículo recorre tres grandes períodos históricos: el período colonial; el siglo XIX hasta fines del XX; y el inicio del siglo XXI. Se trata de un análisis transdisciplinario de los puntos de vista históricos, sociales, demográficos, legales y jurídicos, focalizándose en el desarrollo de esas situaciones, sea por persistencias y/o cambios; quién y cuáles son los actores involucrados y su importancia en la elección de los futuros prometidos. En el comienzo, la selección se fundaba en el parentesco y en el territorio, privilegiando la gran red familiar solidaria en el enfrentamiento de las dificultades de sobrevivencia. Con los avances de la industrialización, de la urbanización, de la tecnología y de la comunicación, además del crecimiento de la importancia de las personas, las elecciones se fueron transformando, disminuyendo la dependencia de la estructura familiar y aumentando la elección personal y afectiva, influenciadas por las variadas formas de cambios sociales, demográficos, jurídicos.

Palabras-clave: Elección del cónyuge. Noviazgo. Compromiso. Edad de los cónyuges.

\section{Abstract}

\section{Choice of spouse}

This article focuses on the topics of courtship and engagement, the age at which persons marry and age differences between spouses. The text briefly describes three long historical periods, namely, the colonial period, from 19th to the late 20th centuries, and the early 21 st. The discussion involves a multi-disciplinary analysis from the historical, social, demographic and legal points of view, and deals especially with the developments of these situations, either through persistence or due to change. Also considered are the actors involved and their importance in the choices of their future wife or husband. In the earliest period studied the choice was based on kinship and 
territory, with special importance given to broad family networks, which participated in facing the difficulties involved in survival. With the advances of industrialization, urbanization, technology and communications, and the greater importance given to the individual, the question of who was to choose the spouses evolved. Dependence on the family structure became less and less important and personal and emotional preferences became more determinant, influenced by various types of social, demographic and legal changes.

Keywords: Choice of spouse. Courtship. Bride and groom. Age of spouses.

Recebido para publicação em 24/07/2008. Aceito para publicação em 18/05/2009. 